\title{
OPEN ACCESS AND EPISTEMIC EQUALITY
}

\author{
Dirk Postma \\ University of South Africa \\ Email: dirkjvr.postma@gmail.com
}

Education as Change has taken the step to publish open access gratis and libre $e^{l}$ under a Creative Commons license, thereby ending its 8 year subscription-based commercial publishing model. This shift to open access is done in the spirit of the Budapest Open Access Initiative (2002). We adhere to the open access commitment defined by Suber $(2012,4)$ as 'digital, online, free of charge, and free of most copyright and licensing restrictions'. The journal maintains the same editorial processes and policies and indexing services. It is now also visible on the ScieloSA ${ }^{2}$ platform. Authors maintain copyright as stipulated under the Creative Commons licensing agreement (CC BY NC ND). ${ }^{3}$ This means that the work could be freely distributed and reproduced as long as credit is given to the author and it is not used for commercial purposes.

This transition to open access is motivated by a commitment to critical research that aims to promote education as empowerment by analysing and resisting all forms of domination and by promoting equality, dignity, justice and freedom. Central to this research is the promotion of epistemic equality, the equal opportunity of the marginalised in particular to contribute towards the global production of knowledge. Open access to knowledge is a necessary condition for the production of knowledge. It is therefore of particular importance for critical research to include the voices of the marginalised and to engage with the conditions of the dominated. It positions itself in support of the equal participation of the Global South ${ }^{4}$ in the production of knowledge. The marginalised are not only the object of research, but have to play an active role as subjects of research. A

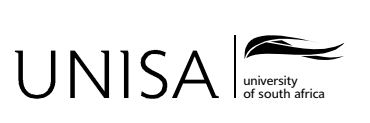

Education as Change

Volume 20 | Number 2 | 2016 | pp. 1-10

www.educationaschange.co.za

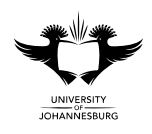

DOI: http://dx.doi.org/10.17159/1947-9417/2016/1603 Print ISSN 1682-3206 | Online 1947-9417

(C) 2016 The Author(s) 
critical journal should therefore not only be freely available to marginalised groups, but should also provide an open opportunity to such groups to produce knowledge.

It seems that these principles of availability and participation are not generally appreciated in critical research that is often caught up in the political economy of commercial publishing. The lack of urgency to open up knowledge is apparent when critical research is compared with another meaning of 'critical' such as in critical medical research. Critical here takes on the meaning of 'crisis' when dealing with matters with life- and environmentally-threatening consequences. In these fields a very strong awareness is present for knowledge to be open and free. ${ }^{5}$ The same awareness and urgency does not seem to be present in many instances of critical research, judging from the many critical journals that either require relatively high article processing charges (APC) or are costly to access. The impression therefore remains that a significant part of critical work is mainly meant for other scholars and it excludes the Global South. There are of course many notable exceptions and one has to acknowledge the complex politics of academic careers and of publishing. The distribution and production of critical knowledge remains a central concern. What and who inform critical perspectives and to whom are these made available? Stripas $(2010,20)$ reminds us of Stuart Hall's frustration with the lack of political effectivity of cultural studies, 'its insubstantiality, how little it registers, how little we have been able to change anything or get anybody to do anything'.

Both equal access to knowledge and the equal production of knowledge are jeopardised when knowledge is privatised and commodified. The privatisation of knowledge is as problematic in critical research concerned about issues of justice as it is in 'crisis' research. One of the most prominent forms of domination in the global information society relates to the politics of knowledge driven by commercial publishers. Various researchers have commented on issues such as the increased cost of journal publications and the large profit margins of commercial publishers (Bergstrom 2001; Bergstrom \& Bergstrom 2004; Striphas 2010, 7, 11), the controversial political involvement of publishers (Striphas 2010, 7, 20) and the active and free participation of authors that serve commercial interests. Frosio (2014, $23 \mathrm{ff}$.) shows further that intellectual property (IP) legislation such as copyright contributes towards the commodification and privatisation of knowledge. He argues that the focus in IP rights shifts from the protection of the intellectual labour of the academic towards the commercial ownership of knowledge when authors are required to transfer their copyright to publishers. Striphas $(2010,5)$ points to the alienating effect of the 'ritual signing of journal publication contracts'. A substantial part of academic publishing has relatively recently (Frosio 2014, 117) been captured by a small number of agents (Striphas 2010,10) with the result that an important common good became concentrated in the hands of a few private owners (Gray 2008, 21). The monopoly of such a 'high concentration' inevitably leads to price increases (Frosio 2014, 119). The increase in the profit margins of large academic publishers (Frosio 2014, 124 ff; Fuchs \& Sandoval 
2013) is an indication of the monopolistic power they hold over academic publishing. The oligopoly (Striphas 2010,10) and decreasing library budgets lead to the artificial creation of the scarcity of academic output. The irony is that this accumulation of capital is based on the free labour of authors, editors and reviewers ${ }^{6}$ many of whom experience themselves the effects of this scarcity.

The privatisation and commodification of knowledge increase epistemic inequalities. The Global South is further marginalised through the cumulative effect of the monopoly of knowledge production and distribution, the unprecedented increase in subscription fees, and the impoverishing effects of changing exchange rates. Commercially bundled journals are not available to trade unions, community organisations, cultural groups, environmental groups and activists who do not have access to large libraries. Truth $(2012,59)$ comments on the North/South divide where 'high-status' knowledge is carefully managed by commercial publishers and reinforced through commercial indexing services (see Gevers \& Mati 2006, 119). Although knowledge production proliferates through OA publications, they remain of a relatively low status. Africa is still for Gray $(2008,51)$ 'the silent continent, its voice hardly heard in either print or in digital research communications'.

The inhibition of the knowledge production of the Global South is, according to Santos (2014), detrimental to social sciences. The commodification barrier inhibits the availability and distribution of the 'epistemologies of the south' and entails an 'epistemicide'.

Unequal exchanges among cultures have always implied the death of the knowledge of the subordinated culture, hence the death of the social groups that possessed it. In the most extreme cases, such as that of European expansion, epistemicide was one of the conditions of genocide. (Santos 2014, 149)

Epistemic inequality of knowledge underlies other forms of inequality. Access to and the production of knowledge is an important terrain of contest in what Hardt and Negri describe as the current immaterial form of capitalist production. This refers to the 'knowledges, information, images, affects, and social relations which are subsequently expropriated by capital to generate surplus value' in the 'new forms of exploitation of biopolitical labor' (Hardt \& Negri 2009, 139). The monopolisation of knowledge production and distribution is particularly problematic since its publication in journal articles and books is a 'non-substitutable good' (also called non-fungible by Striphas $[2010,15])$ and the market is relatively inelastic. For Bergstrom and Bergstrom (2004) academic articles are not substitutable but complementary. With this they mean that an article cannot simply be substituted for another as may be the case with commodities because they are used in complementary ways by researchers. The lack of access to a particular article constitutes therefore for a researcher a limitation to the knowledge available in a field. The Global South experiences epistemic exclusion when such nonsubstitutable goods are commodified and privatised. 
In order to address epistemic inequalities it is important for critical research to resist those systems and structures that contribute to new forms of domination and marginalisation, particularly capitalist accumulation and the associated forms of exclusion and exploitation, and to create practices of inclusion and equality. Sterne $(2013,322)$ provides a challenge to critical scholars within a cultural studies learned organisation such as the National Communication Association (NCA) to rethink the relation with a commercial publisher. Such critical authors 'could lead a movement for NCA to end its affiliation with Taylor \& Francis, and to make all its journals open access'. Critical research that does not make itself accessible to the poor, the subjugated and the marginalised is in conflict with itself. ${ }^{7}$ In order to address these inequalities, it is important for critical research to engage with the political economy of commercial publishing (see Frosio 2014, 118).

This engagement deals with both opening up access to knowledge and with opening up opportunities to produce knowledge. While the debate is largely about open access to knowledge, inadequate attention is given to the 'open' production of knowledge. While access to knowledge is one of the necessary conditions for participating in its production, another necessary condition is access to publications of choice. The question is therefore not only how free knowledge is made available, but also how freely available the opportunities are for producing knowledge. Open access publication is necessary in order to make knowledge freely available, particularly to those communities who may need it most (being knowledge of a critical nature). Open participation in the production of knowledge is necessary in order to provide an equal voice to the Global South. This participation is, however, curtailed when the cost for open access is placed on the author or the institution. While Scherlan and Robinson (2008), editors of the Journal of Criminal Justice Education, present an argument for open access on the basis of the theories of justice of Rawls and Miller, they only refer to access to, and not to the production of, knowledge. While their argument for open access is important, the problem lies, however, with the gold ${ }^{8}$ open access model they propose. In this particular case it means that an author who wants to publish an open access article has to pay $\$ 2950$ (http://goo.gl/VL52uG). Though access to such articles is free, the option to have an article published open access in such a journal is therefore only available to a small number of scholars who could afford it personally or institutionally. As a result academics in the Global South are excluded from producing open access knowledge in such journals. This does not serve justice as defined by Rawls:

Social and economic inequalities are to be arranged so that they are both (a) to the greatest expected benefit of the least advantaged and (b) attached to offices and positions open to all under conditions of fair equality of opportunity. (Rawls 1999, 53)

Justice is not to be expected from open-access commercial publishing since it deepens divisions and 'not only implies unequal access, but is also a structurally-racist practice that disadvantages scholars and institutions in developing countries' (Fuchs \& Sandoval 
2013, 439). In contrast to this, justice could be better served when an open opportunity is given to the marginalised to produce and publish their knowledge. In order to distinguish the model of open access where the author is charged with high fees, Fuchs and Sandoval (2013) propose a 'diamond' model where moderate or no fees apply. This distinction between 'gold' and 'diamond' is important to separate bona fide OA journals from the for-profit ones. Where gold open access fits the for-profit model of commercial publishers, the diamond model refers to those publications that are either free for the author or that have a relatively low APC to cover the costs of publication. The problem with the relatively high APCs is that, while knowledge is accessible in the Global South, it is not necessarily produced by the Global South. 'The result is that knowledge locally produced and published commercially become inaccessible to the context where it originates' (Frosio 2014, 111). This contributes to the 'lack of visibility of research in the global South' (Frosio 2014, 111). The introduction of the category of the diamond model aims to overcome these two restrictions by describing a form of publication where the Global South has an equal opportunity to both access and produce knowledge.

Epistemic equality can only be promoted when knowledges from the Global South proliferate. Since inequalities in the production of knowledge underlie other forms of inequalities, the location of knowledge and the subject producing the knowledge are highly significant. This situatedness means that all knowledge (Haraway 1988) is produced in a particular historical location by embodied subjects who can only present a partial perspective. Notions of objectivity based on the absence of the geopolitical subject of knowledge production only serve to conceal relations between knowledge, power and interests. Objectivity lies, for Haraway, not only in the focus on the objects of knowledge, but also in the plural knowledges reflecting various partial perspectives. Among the different knowledges, Haraway claims that subjugated knowledges are in a preferred position 'because in principle they are least likely to allow denial of the critical and interpretive core of all knowledge' (Haraway 1988, 584). It therefore matters what the 'race', gender, class, ethnicity, gender and geopolitical location of the producer of knowledge are. It is important for the global knowledges project to fully include knowledges from the Global South. In light of the dominance of the Global North in the production of knowledge, Gray $(2008,51)$ wants to hear the silent voice of Africa and Grosfoguel wants to hear the voice of the subaltern:

The complicity of the social sciences with the coloniality of power in knowledge production and imperial global designs makes a call for new institutional and non-institutional locations from which the subaltern can speak and be heard. (Grosfoguel 2008, 15)

Santos also emphasises the need for subaltern knowledges because for him the western rationality has become 'lazy' (Santos 2014, 262) by failing to appreciate the rich variety of knowledges. Such richness is better appreciated through an 'ecology of knowledges': 
Would not the historical opportunity for the global North to learn from the experiences of the global South lie precisely here? The truth of the matter is that, after five centuries of 'teaching' the world, the global North seems to have lost the capacity to learn from the experiences of the world. In other words, it looks as if colonialism has disabled the global North from learning in noncolonial terms, that is, in terms that allow for the existence of histories other than the universal history of the West. (Santos 2014, 38)

The contribution of the subaltern is needed to expand the 'common' which does not only refer to the natural resources available to everyone, but also to a common which is

dynamic, involving both the product of labor and the means of future production. This common is not only the earth we share but also the languages we create, the social practices we establish, the modes of sociality that define our relationships, and so forth. (Hardt \& Negri 2009, 139)

In order to expand the common more languages, social practices and, one could add, knowledges have to be included and recognised. Ways need to be found to become more inclusive and to avoid the strategies of exclusion and elitism. In the words of Santos

There is a need to decolonise knowledge production from the dominant universe of the west in order to create a pluriverse where different knowledges could thrive in the development of 'ecologies of knowledge'. (Santos 2014, 300)

I have argued here that the open access movement provides an important platform for the voice of the subaltern and for its contribution to the body of knowledge all humans share. The opening up of both the distribution and production of critical research is as necessary for human well-being as is crisis-research related to human-ecological survival in risk areas such as food security, contagious diseases and environmental degradation. Survival (human and nonhuman) on the planet is dependent on mutual understanding and respect developed by ecologies of knowledge without which crisisresearch would understand issues only partially. The contribution of the Global South to the production of knowledge is important in order to counter a tendency in critical research to only speak to itself and on behalf of others.

\section{THIS ISSUE}

The first two articles in this issue deal with issues of teachers' professional development. Robinson investigates how 'Professional Practice Schools' could address educational inequalities in South African schools by building closer school-university partnerships that support student teachers. Robinson not only asks about the efficiency of interventions, but also investigates how social justice could be promoted through the development of professional agency.

Slonimsky draws lessons for teacher development in South Africa from Durkheim's courses in educational theory. In contrast to the current shift towards subject knowledge and pedagogy, she emphasises the need for educational theory in order to develop critical 
thinking and autonomy. She points to a curriculum paradox in South Africa: on the one hand teacher heteronomy induced by an authoritarian state and prescribed curricula and, on the other hand, the expected teacher autonomy and critical thinking. In order to address the curriculum paradox teachers socialised in an authoritarian regime have to become autonomous critical thinkers. This is where the insights of Durkheim are important, for Slonimsky. Teachers should not learn about educational theories, but they should be able to 'reflect methodologically'. This will enable teacher critical reflexivity and autonomy in a context of changing policies.

The following two articles are related to Slonimsky's notion of critical thinking. Cooper investigates how critical consciousness could be developed through dialogue in the educational space of a radio show. The research included youths from schools that are economically, socially and culturally diverse. The dialogues reflected the particular identities and historical positions of participants. Cooper reflected on the ways critical consciousness could be developed by reflecting on language and 'rationality'. He found that the institutional culture of 'elite' schools tends to dominate the dialogue and prevent critical consciousness from emerging. He subsequently emphasises the importance of facilitation in order to keep the dialogue open and from lapsing into entrenched positions of difference.

While it is important to develop critical consciousness at all educational levels, the study of Odrowaz-Coates shows how this could be developed among both 5-10 year olds and university students through the use of film. She demonstrates how issues of social exclusion, power/ knowledge, violence, and agency could be addressed through the careful selection of media and the mediation of learning processes.

The following two articles relate critical consciousness with affect. Breshears and Lubbe-de Beer investigate the experiences of school children who have lesbian parents. They found that these children are subjected to a high level of bullying and teasing from other children and that schools themselves display a high level of insensitivity towards family diversities. The research made a number of valuable recommendations for schools to develop understanding and sensitivities related to differences in gender and sexual preference.

Magano and Berman investigate the identity of the so-called 'born-frees' in South Africa. Their research is located within the context of the Life Orientation school curriculum that deals with 'self and society'. Their investigation shows how the identities of the 'born-free' girls are established through complex negotiations with peers, parents, traditions and a dominant American-Western culture. They recommend that the Life Orientation pedagogy should do more to assist these girls in defining themselves within a context of conflicting demands.

The following two articles deal with issues of equality and inclusion in education. Sibomana focuses on language exclusion when he reflects critically on the role academics play as border guards more than as facilitators of learning. He argues that academic merit is established on the basis of language use, rather than on the content students 
produce. His investigation into the lack of academic success of a number of Rwandese students reveals that their main difficulty is the acquisition of the particular discourse embedded in the programme. While students were not adequately supported to acquire the necessary discourse, the discourses they already possess are not acknowledged and used in the development of their academic competence.

Robins and Fleisch investigate the social movement Equal Education which has become a significant activist for change in South African education. The authors contrast the 'slow activism' of this movement with the kind of activism of the 2015 student protest movements. They show that Equal Education addresses some of the basic issues that are detrimental to educational equality and quality such as health and late-coming. While university students and advisors play a role, the movement is largely driven by school children. In the process they learn how to be powerful through the power of their own learning.

Keane, Khupe and Muza contribute towards indigenous research methodologies by investigating how the life experiences of researchers shape their research projects. They want to break with notions of objectivity and neutrality in science by investigating the close relation between research and researcher. In this process they report on the life stories of three researchers: in one case an account is given of the experiences of participative research within a rural community; in another it is shown how a researcher is motivated by the question of relevant science education for a particular school and community; in the third case the author investigates the relation between science understanding and traditional beliefs. From these life stories they conclude that there is more than one way of knowing and being in the world than what is made possible in traditional concepts of science.

Related to the epistemic shift in indigenous research methodologies is the shift Paphitis and Kelland found is needed for South African universities to develop civicminded graduates through service learning and community engagement. They point to the schizophrenia in higher education that attempts to both serve neoliberal goals and develop civic-minded citizens. They argue that universities have to challenge the status quo by changing their institutional culture and by transforming students by developing new habits of mind and frames of reference. The authors found that the pedagogy and practices of service learning are not yet adequate to effect changes in institutional culture and to develop civic-minded graduates. They show that the epistemic shift is related to the mutuality between community-based and university learning.

Another focus on the transformation of universities is present in Jacobs's analysis of institutional documents of Stellenbosch University. She notes differences between changes in institutional culture and the demands for real transformation. She detects a visionary awareness of diversity, inclusivity and a closer alignment between institutional culture and transformation. However, she expresses concern about the depth of processes of transformation that are mainly equated with the redesign of core 
processes. She concludes on a hopeful note about the intentions and promises in various official statements.

Within the context of endemic violence and injustice in schools and society, John reports on a peace education project with postgraduate students in education. The students were enabled to use a conflict mapping tool to explore areas of conflict, injustice and violence in their schools. Participants (teachers and children) are given the opportunity to map graphically areas in the school associated with conflict, injustice and violence. This mapping by different participants creates an awareness of unexpected spaces of risk in which various agents are implicated. The programme draws on a Freirean framework of critical reflection, dialogue and action in order to conscientise and develop teachers as critical change agents. The participants were enabled to reflect critically through dialogical learning on the spaces of violence in schools and to find suitable strategies to reconfigure such spaces.

\section{NOTES}

1 These distinctions are made by Suber (2012). Gratis removes price barriers and libre means that there are as few as possible restrictions on the use of the content.

$2 \mathrm{http}: / /$ www.scielo.org.za/scielo.php?script $=$ sci_issues\&pid=1947-9417\&lng=en\&nrm=iso

3 https://creativecommons.org/licenses/

4 'Global North' and 'Global South' do not simply refer to a geographic distinction, but rather to the benefactors and victims of globalisation and neoliberalism. The 'Global South' refers to the geopolitical and geo-economical marginalisation driven by capitalism and neoliberalism.

5 See the open access policy of the World Health Organization (http://www.who.int/about/ policy/en/), or the case of Jack Andraka (https://goo.gl/bsVPMp).

6 Bergstrom and Bergstrom $(2004,1)$ insightfully contrast the business models of car and journal production which illustrates the free labour underlying the latter.

7 Hall $(1992,281)$ reminds us of Gramsci's appeal to organic intellectuals to make their insights available to those who do not belong to the intellectual class.

8 Gold refers to the free delivery of the article by a journal and green to the free delivery of a pre- or post-print version in a repository or by some other means.

\section{REFERENCES}

Bergstrom, T.C. 2001. Free labour for costly journals? Journal of Economic Perspectives 15(4): 183198.

Bergstrom, T.C. and C.T. Bergstrom. 2004. Will open access compete away monopoly profits in journal publishing? Retrieved from: http://octavia.zoology.washington.edu/publishing/ BergstromAndBergstrom04b.pdf (accessed 25 August 2016). 
Budapest Open Access Initiative. 2002. BOAI Declaration. Retrieved from: http://www. budapestopenaccessinitiative.org/read (accessed 26 August 2016).

Frosio, G.F. 2014. Open access publishing: A literature review. CREATe Working Paper 2014/1. Retrieved from: http://www.create.ac.uk/publications/000011 (accessed 15 July 2016).

Fuchs, C. and M. Sandoval. 2013. The diamond model of open access publishing: Why policy makers, scholars, universities, libraries, labour unions and the publishing world need to take non-commercial, non-profit open access serious. tripleC 13(2): 428-443.

Gevers, W. and X. Mati, eds. 2006. Report on a strategic approach to research publishing in South Africa. Pretoria: Academy of Science of South Africa. Retrieved from: http://www.assaf.org. za/files/2011/02/2466-ASSAF-Strategic-approach-to-research-publishing-2.pdf (accessed 3 August 2016).

Gray, E. 2008. A critique of research dissemination policy in South Africa, with recommendations for policy reform. International Policy Fellowship Program Open Society Institute. Retrieved from: www.policy.hu/document/200808/eve.gray.pdf\&letoltes=1 (accessed 15 August 216).

Grosfoguel, R. 2008. A decolonial approach to political-economy: Transmodernity, border thinking and global coloniality. Kult 6. Retrieved from: http://www.eurozine.com/articles/2008-07-04grosfoguel-en.html (accessed 17 August 2016).

Hall, S. 1992. Cultural studies and its theoretical legacies. In Cultural Studies. Edited by L. Grossberg, C. Nelson and P. Treichler, 277-294. New York and London: Routledge.

Haraway, D.J. 1988. Situated knowledges: The science question in feminism and the privilege of partial perspective. Feminist Studies 14(3): 575-599.

Hardt, M. and A. Negri. 2009. Commonwealth. Cambridge MA: Harvard University Press.

Rawls, J. 1999. A theory of justice. Revised edition. Cambridge MA: Harvard University Press.

Santos, B. de S. 2014. Epistemologies of the South. Justice against epistemicide. London: Routledge.

Scherlen, A. and M. Robinson. 2008. Open access to criminal justice scholarship: A matter of social justice. Journal of Criminal Justice Education 19(1): 54-74.

Sterne, J. 2013. Keyword: Journal. Communication and Critical/Cultural Studies 10(2-3): 319-323.

Striphas, T. 2010. Acknowledged goods: Cultural studies and the politics of academic journal publishing. Communication and Critical/Cultural Studies 7(1): 3-25.

Suber, P. 2012. Open access. Cambridge MA: MIT Press.

Truth, F. 2012. Pay big to publish fast: Academic journal rackets. Journal for Critical Education Policy Studies 10(2): 54-105. 